\title{
OPEN Sodium salt-assisted low temperature activation of bentonite for the adsorptive removal of methylene blue
}

\begin{abstract}
Siti Fairos Ab Shattar \& Keng Yuen Foo
The sodium salt-assisted low temperature activation of bentonite (BB) was attempted. The unique features of the raw bentonite and BB were characterized with respect to the morphological, functional, and textural analysis. The adsorptive behaviour was evaluated by adopting methylene blue (MB) as the model pollutant via batch adsorption experiment. The experimental data were fitted to the non-linear isotherm equations (Freundlich, Langmuir, and Temkin), while the adsorption modelling was interpreted by the pseudo-first order, pseudo-second order and Elovich models. The adsorptive mechanism was ascertained according to intraparticle-diffusion and boyd models. The intercalation of sodium salt into the bentonite surface give rise to the specific surface area and total pore volume from 120.34 to $426.91, \mathrm{~m}^{2} / \mathrm{g}$ and 0.155 to $0.225 \mathrm{~cm}^{3} / \mathrm{g}$, respectively, indicating a large proportion of the newly formed surfaces may be connected to new pore walls, associated with the silanol $(\equiv \mathrm{SiOH})$, and aluminol $(\equiv \mathrm{AIOH})$, and hydroxyl $(-\mathrm{OH})$ groups for the possible entrapment MB onto the adsorbent. The equilibrium data was satisfactory described by the Langmuir isotherm and pseudo-second order model, with a monolayer adsorption capacity for MB of $318.38 \mathrm{mg} / \mathrm{g}$, while the thermodynamic study verified spontaneous, feasible, and endothermic of the adsorption process.
\end{abstract}

In general, bentonite, a multi-components mixture of clay and minerals of aluminium phyllosilicate (hydrated aluminasilicate), is a two-dimensional nano-material, which fall under the smectite-class mineral of the montmorillonite ${ }^{1}$. Consist of a multi-expandable layered structure, bentonite owns a net negative surface charge, mainly ascribed to the isomorphous substitution of $\mathrm{Al}^{3+}$ for $\mathrm{Si}^{4+}$, and $\mathrm{Mg}^{2+}$ for $\mathrm{Al}^{3+}$ within the tetrahedral and octahedral clay framework. The charge could be compensated by the exchangeable cations $\left(\mathrm{Na}^{+}\right.$and $\left.\mathrm{Ca}^{2+}\right)$, which are known to be the inter-layer hydrated cations ${ }^{2}$. The unique feature of bentonite is the formation of thixotrophic gels in the aqueous medium to enlarge its volume at 12-15 times of its dry bulk. When bentonite is in contact with water, the layered structure will expand with the hydration of $\mathrm{Na}^{+}$and $\mathrm{Ca}^{2+}$, to turn into a hydrophilic characteristic $^{3}$. The adsorptive behavior of the natural bentonite could be specifically altered for the targeted pollutants. One of the possible route is the exchange of quaternary ions $\left(\mathrm{R}_{4} \mathrm{~N}\right)^{+}$with the Group IA and IIA metal ions present between the aluminum and silica layers ${ }^{4}$. The reduction of the hydrophilicity could be represented by the expulsion of metal ions with the coordinated water molecules, and in the alkaline conditions, this negative load would be screened, which in turn favouring the approximation of the tactoids, and rearrangement of the clay particles ${ }^{5}$. Therefore, different routes have recently been proposed by the environmentalists to enhance the adsorption capability of the bentonite derivatives.

Amongst methods of beneficiation for bentonite adsorption process are pillaring, calcinations, acid treatment and salt exchange. These modifications may involve the changing of textural or structural properties, specific surface area, and porosity, following the incorporation of new functionalities or compositional changes to generate and/or strengthen the surface-active sites. The intercalation of hydroxyl aluminum, iron, titanium, chromium and zirconium cations, also known as basal plane spacing (001) or pillaring step may expand the clay layer, to be transformed into stable porous adsorbents. However, the pillaring solutions usually takes a longer preparation duration of $3 \mathrm{~h}$ to $10 \mathrm{day}^{6}$. Calcination could assist in the thermal treatment for better adsorptive uptake of clay minerals, driven by the loss of adsorbed moisture, structural changes, textural properties, and dispensability of bentonite in the aqueous solution ${ }^{7}$. Nevertheless, the applied treatment process and dehydration reaction with the collapse of the clay structure may remove the non-clay matter, subsequent by the octahedral 
cation movement within the interlayer clay sheets. Acid treatment involves the penetration of protons into the interlayer of bentonite substituting the exchangeable cations of the clay minerals, and improve the porosity, surface active sites and mineral purity of the external surface ${ }^{8}$. The partial dissolution effect of the excessive acid treatment however, may reduce the adsorptive uptake by at least $30 \%$. Therefore, a call for the continuous research in establishing a simple modification technique, eco-friendly, with less energy consumption, time saving, and effective for environmental conservation is deeply required.

In a study conducted by Kaufhold and Dohrmann ${ }^{9}$, a close reaction system between 36 bentonites and $\mathrm{NaCl}$ solution $(6 \mathrm{M})$ was conducted at $60^{\circ} \mathrm{C}$ for 5 months. Compositional analysis indicated that no obvious mineral alteration was detected, while the bentonite derivatives were highly stable in the $\mathrm{NaCl}$ solutions to support the reaction with exceeding 24 weeks. The reported results were supported by Stawiński et al. ${ }^{10}$ that no irreversible changes could be identified of the sodium salt treated adsorbent, indicating redeposition of the dissolute elements as hydroxides. These Al, Mg and Fe hydroxides that could be adsorbed by the broken edge sites, or present concurrently may appear as the interlayer or coating surface between the clay minerals. The reactivity of this phase is significantly higher than the free hydroxides, contributed by the three major surface binding sites, notably permanent charged siloxane surface, mono-coordinated and newly formed hydroxide species within the clay edges $^{11}$. With the aforementioned, in this work, the sodium salt-assisted low temperature activation of highly porous bentonite derived adsorbent (BB) was carried out by varying the modification ratio. The specific features were evaluated with respect to the morphological characteristic, surface functionalities and textural property. Methylene blue was adopted as a model adsorptive behaviour. Non-linear isotherm models and kinetic equation were applied for the data simulation. The adsorptive mechanism was ascertained by the intra-particle diffusion and Boyd models, whereas the thermodynamic behavior were critically elucidated.

\section{Methodologies and materials}

Functionalized bentonite. Raw bentonite applied in this work was commercially acquired from Sigma Aldrich, Malaysia. The activation step was performed by mixing the raw bentonite with $\mathrm{NaCl}$ solution at $70{ }^{\circ} \mathrm{C}$ for $1 \mathrm{~h}$, with the impregnation ratio (IR) given by:

$$
\mathrm{IR}=\frac{W_{\text {Bentonite }}}{W_{\mathrm{NaCl}}}
$$

where $W_{\text {bentonite }}$ and $W_{\mathrm{NaCl}}$ are the dry mass of bentonite (g) and $\mathrm{NaCl}(\mathrm{g})$. The activated bentonite (BB) was collected by centrifugation, subsequent by washing extensively with deionized water (DW) until the washing solution reached to a neutral $\mathrm{pH}$ before it was dried and stored in a sealed bottle.

Model pollutant. Methylene blue (MB), a model pollutant with low biodegradability in nature was adopted. The chemical structure, molecular weight and $\lambda_{\max }$ of $\mathrm{MB}$ are derived as $\mathrm{C}_{16} \mathrm{H}_{18} \mathrm{C} \cdot \mathrm{N}_{3} \mathrm{~S}_{3} \cdot \mathrm{H}_{2} \mathrm{O}, 373.91 \mathrm{~g} / \mathrm{mole}$ and $663 \mathrm{~nm}$, respectively. It could be dissociated into a $\mathrm{MB}^{+}$cation and $\mathrm{a} \mathrm{Cl}^{-}$anion in the aqueous medium, with the dehydrated features of $14.3 \AA$ in width, $6.1 \AA$ in depth, $4 \AA$ in thickness, and the molecular volume and molecular diameter of $241.9 \mathrm{~cm}^{3} /$ mole and $0.8 \mathrm{~nm}$, respectively. An appropriate amount of MB was dissolved in DW for preparation of standard stock solution, and working solutions was acquired by successive dilutions.

Adsorption experiments. The adsorption experiments were performed in the conical flasks containing $200 \mathrm{~mL}$ of adsorbate solution and $0.2 \mathrm{~g}$ of $\mathrm{BB}$ at the pre-determined concentrations from 50 to $500 \mathrm{mg} / \mathrm{L}$. The solution mixture were agitated at $130 \mathrm{rpm}$ and $30^{\circ} \mathrm{C}$ for $24 \mathrm{~h}$, and the concentration of the supernatant solution was analyzed at $663 \mathrm{~nm}$ using a UV-Vis spectrophotometer (Shimadzu-1800). The experiments were conducted in triplicates, and the equilibrium uptake, $q_{\mathrm{e}}(\mathrm{mg} / \mathrm{g})$, was determined by:

$$
q_{\mathrm{e}}=\frac{\left(C_{0}-C_{\mathrm{e}}\right) V}{W}
$$

where $C_{0}$, and $C_{\mathrm{e}},(\mathrm{mg} / \mathrm{L})$ are the initial and equilibrium liquid-phase concentration of $\mathrm{MB}$, and $V$ and $W$ is denoted to volume of adsorbate solution (L), and dry mass of $\mathrm{BB}(\mathrm{g})$, respectively.

To better correlate the experimental data with the isotherm equations, the non-linearized Langmuir ${ }^{12}$, Freundlich ${ }^{13}$ and Temkin ${ }^{14}$ isotherm models have been adopted:

$$
\begin{gathered}
q_{\mathrm{e}}=\frac{Q_{0} K_{\mathrm{L}} C_{\mathrm{e}}}{1+K_{\mathrm{L}} C_{\mathrm{e}}} \\
q_{\mathrm{e}}=K_{\mathrm{F}} C_{\mathrm{e}}^{1 / n} \\
q_{\mathrm{e}}=B \ln \left(A C_{\mathrm{e}}\right)
\end{gathered}
$$

where $Q_{0}(\mathrm{mg} / \mathrm{g}), K_{\mathrm{L}}(\mathrm{L} / \mathrm{g})$ and $K_{\mathrm{F}}(\mathrm{mg} / \mathrm{g})(\mathrm{L} / \mathrm{mg})^{1 / n}$ are the Langmuir isotherm constants for adsorption capacity, adsorption energy, and Freundlich isotherm constant respectively, where $1 / n$ is a measure of adsorption intensity, and $B=R T / b_{\mathrm{T}}$, with $b_{\mathrm{T}}(\mathrm{J} / \mathrm{mole}), R(8.314 \mathrm{~J} / \mathrm{mole} K), T(\mathrm{~K})$ and $A(\mathrm{~L} / \mathrm{mole})$ are the heat of sorption, universal gas constant, absolute temperature and equilibrium binding constants, respectively. 
For the assessment of the non-linear isotherm models, a trial-and-error procedure was performed to maximize the coefficient of determination $R^{2}$, between the experimental data and isotherms in the solver add-in with Microsoft's spreadsheet, Microsoft Excel, defined as:

$$
R^{2}=\frac{\left(q_{\mathrm{e}, \text { meas }}-\bar{q}_{\mathrm{e}, \mathrm{calc}}\right)^{2}}{\sum\left(q_{\mathrm{e}, \mathrm{meas}}-\bar{q}_{\mathrm{e}, \mathrm{calc}}\right)^{2}+\left(q_{\mathrm{e}, \mathrm{meas}}-q_{\mathrm{e}, \mathrm{calc}}\right)^{2}}
$$

where $q_{\mathrm{e}, \text { calc }}, \bar{q}_{\mathrm{e}, \mathrm{calc}}$ and $q_{\mathrm{e} \text {,meas }}$ are the predicted, average mean and measured methylene blue concentration at equilibrium deduced from the isotherm model. The experimental data then was validated by the root-meansquare deviation $(R M S D)$, given by:

$$
R M S D=\frac{\sqrt{\sum_{i=1}^{n}\left(q_{\exp }-q_{\mathrm{p}}\right)^{2}}}{n-1}
$$

where $n$ indicating the total data points, while the experimental and predicted adsorption capacity are represented by corresponding $q_{\text {exp }}(\mathrm{mg} / \mathrm{g})$ and $q_{\mathrm{p}}(\mathrm{mg} / \mathrm{g})$, respectively.

The changing solution $\mathrm{pH}$ on the adsorptive performance was conducted at the solution $\mathrm{pH}$ from 1 to 12 , at the $\mathrm{BB}$ dosage of $0.2 / 200 \mathrm{~mL}$, initial concentration at $500 \mathrm{mg} / \mathrm{L}$ and operating temperature of $30{ }^{\circ} \mathrm{C}$. The $\mathrm{pH}$ adjustment was conducted by using $0.1 \mathrm{M}$ hydrochloric acid $(\mathrm{HCl})$ and/or sodium hydroxide $(\mathrm{NaOH})$, and the measurement was ascertained using a $\mathrm{pH}$ meter.

Kinetic modelling. For the interpretation of kinetic analysis, the solution samples were measured at prescribed time interval, and the adsorptive uptake at time $t, q_{\mathrm{t}}(\mathrm{mg} / \mathrm{g})$, was determined by:

$$
q_{\mathrm{t}}=\frac{\left(C_{0}-C_{\mathrm{t}}\right) V}{W}
$$

where $C_{\mathrm{t}}(\mathrm{mg} / \mathrm{L})$ is denoted as the liquid-phase concentration of MB dye at time, $t$.

It describes the adsorbate uptake, mass transfer, and the equilibrium time of an adsorption process. In this study, the pseudo-first order ${ }^{15}$, pseudo-second order ${ }^{16}$ and Elovich kinetic ${ }^{17}$ equations were adopted for the effective simulation of the equilibrium data, defined as:

$$
\begin{gathered}
\ln \left(q_{\mathrm{e}}-q_{\mathrm{t}}\right)=\ln q_{\mathrm{e}}-k_{1} t \\
\frac{t}{q_{\mathrm{t}}}=\frac{1}{k_{2} q_{\mathrm{e}}^{2}}+\frac{1}{q_{\mathrm{e}}} t \\
q_{\mathrm{t}}=\left(\frac{1}{b}\right) \ln (a b)+\frac{1}{b} \ln t
\end{gathered}
$$

where $k_{1}(1 / \mathrm{h})$ and $k_{2}(\mathrm{~g} / \mathrm{mg} \mathrm{h})$ is the adsorption rate constant for the pseudo-first and pseudo-second order kinetic equation respectively, while $a(\mathrm{mg} / \mathrm{g} \mathrm{h})$ is the initial sorption rate and $b(\mathrm{~g} / \mathrm{mg})$ is related to the extent of surface coverage, and activation energy for chemisorption of the Elovich equation. The suitability of the kinetic models was validated by the correlation coefficient, $R^{2}$, and the normalized standard deviation, $\Delta q$ (\%):

$$
\Delta q(\%)=\sqrt{\frac{\sum\left|\left(q_{\mathrm{e}, \exp }-q_{\mathrm{e}, \mathrm{cal}}\right) / q_{\mathrm{e}, \exp }\right|^{2}}{n-1}} \times 100
$$

where the data points, the experimental and calculated adsorption capacity are represented by $n, q_{\mathrm{e}, \exp }(\mathrm{mg} / \mathrm{g})$ and $q_{\text {e,cal }}(\mathrm{mg} / \mathrm{g})$, respectively.

Adsorption mechanism. The kinetic study explains solute-adsorbent surface interaction during the adsorption process, but does not elucidate the solutes particles diffusion mechanism onto the adsorbent surface. Therefore, the equilibrium data was analyzed according to the Fick's second diffusion law, the Weber and Morris intra-particle diffusion ${ }^{18}$ and the Boyd film diffusion models ${ }^{19}$ :

$$
\begin{gathered}
q_{\mathrm{t}}=k_{\mathrm{pi}} t^{0.5}+C_{\mathrm{i}} \\
B_{\mathrm{t}}=-0.4977-\ln (1-F)
\end{gathered}
$$

where the diffusion rate constant and thickness of the boundary layer could be devoted as $k_{\mathrm{pi}}\left(\mathrm{mg} / \mathrm{g} \mathrm{h}^{0.5}\right)$ and $C_{\mathrm{i}}$, respectively, whereas $B_{\mathrm{t}}$ is a mathematical function of fractional attainment of equilibrium $F$, at any time $t$, given by:

$$
F=\frac{q_{\mathrm{t}}}{q_{\mathrm{e}}}
$$




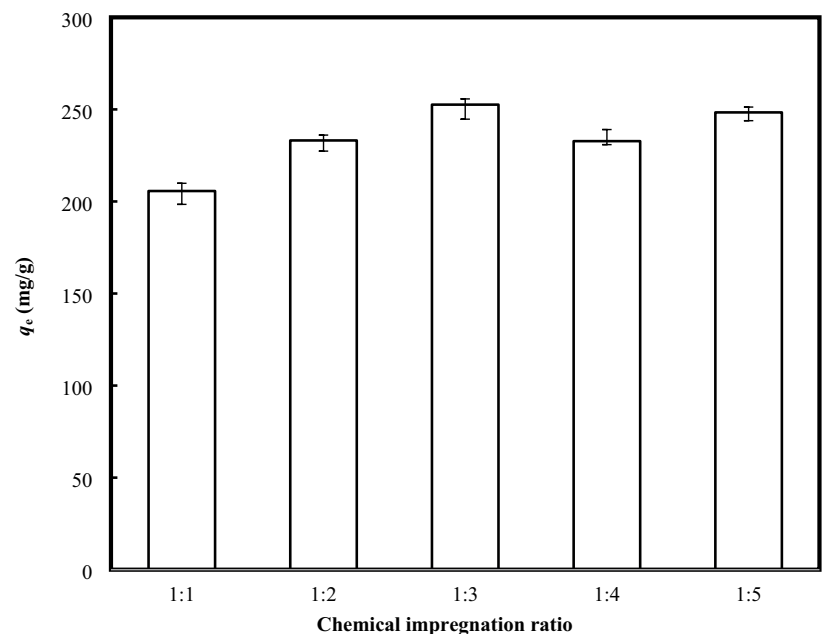

Figure 1. Effects of chemical impregnation ratio on the adsorptive uptake of $\mathrm{MB}$ (Adsorbent dosage $=0.2 \mathrm{~g} / 200 \mathrm{~mL}$; Temperature $=30^{\circ} \mathrm{C}$; Initial concentration $=500 \mathrm{mg} / \mathrm{L}$ ).

Thermodynamic study. Thermodynamic considerations are required for determination of spontaneity nature, high feasibility or energy requirement of an adsorption process ${ }^{20}$. The Gibbs free energy change, $\Delta G^{\circ}$ $(\mathrm{kJ} / \mathrm{mole})$ represents the spontaneity assessment of a chemical reaction, and both changing entropy and energy must be critically identified. Accordingly, the negative $\Delta G^{\circ}$ indicates a high spontaneity and energy of a reaction, specific at a temperature, and the adsorption equilibrium constant $K_{\mathrm{L}}$ could be derived by:

$$
\Delta G^{\circ}=-R T \ln K_{\mathrm{L}}
$$

with $R(8.314 \mathrm{~J} /$ mole $K)$ is the universal gas constant, and $T(K)$ is the absolute temperature. The relation of the equilibrium constant with the changing operating temperature could be acquired from the differential equation proposed by Ho et al. ${ }^{21}$ :

$$
\frac{D \ln K_{\mathrm{L}}}{\mathrm{d} T}=\frac{\Delta H^{\circ}}{R T^{2}}
$$

The integrated Eq. (17) yields:

$$
\ln K_{\mathrm{L}}=-\frac{\Delta H^{\circ}}{R T}+Y
$$

where $Y$ is a constant, and Eq. (18) could be further rearranged in the form of

$$
-R T \ln K_{\mathrm{L}}=\Delta H^{\circ}-T R Y
$$

Let $\Delta S^{\circ}=R Y$.

Substituting Eq. (16) into Eq. (19), $\Delta G^{\circ}$ can be represented by:

$$
\Delta G^{\circ}=\Delta H^{\circ}-T \Delta S^{\circ}
$$

where $\Delta H^{\circ}$ and $\Delta S^{\circ}$ are the standard enthalpy and standard entropy change, respectively.

Physio-chemical characterization. The morphological structure of the functionalized adsorbent was examined by using the scanning electron microscope (Supra 35 VP, Germany) equipped with W-Tungsten filament, with $\mathrm{MnK}_{\alpha}$ as the energy source. The porosity measurement was conducted by the nitrogen adsorption isotherm using the Micromeritics ASAP 2020 analyzer. The Fourier transform infrared spectroscopy (FTIR) analysis was conducted according to the $\mathrm{KBr}$ method using the Perkin-Elmer Spectrum GX infrared spectrometer in the scanning range of $4000-400 \mathrm{~cm}^{-1}$. The point of zero charge, $p H_{\mathrm{pzc}}$ was justified by adjusting the solution $\mathrm{pH}$ of $200 \mathrm{~mL}$ of $0.01 \mathrm{M} \mathrm{NaCl}$ solution to a value between 1 and 12 . The final $\mathrm{pH}$ was measured after 2 days agitation. The point where $p H_{\text {initial }}-p H_{\text {final }}=0$ is $p H_{\text {pzc }}$.

\section{Results and discussions}

Chemical impregnation ratio, IR. A feasible approach to enhance the adsorptive performance of the clay mineral is the alteration of surface chemistry, in which activation agents play a decisive role. During the activation process, the pore system of the clay minerals could be modified, leading to the changing catalytic, adsorptive and environmental functions of the minerals with the improvement on the crystalline structure of the minerals via structural ion dissolution or reorganization of the interior porosity. The effect of $I R$ for the equilibrium uptake of $\mathrm{MB}$ onto $\mathrm{BB}$ is depicted in Fig. 1. It can be clearly found from Fig. 1 that increasing the IR 


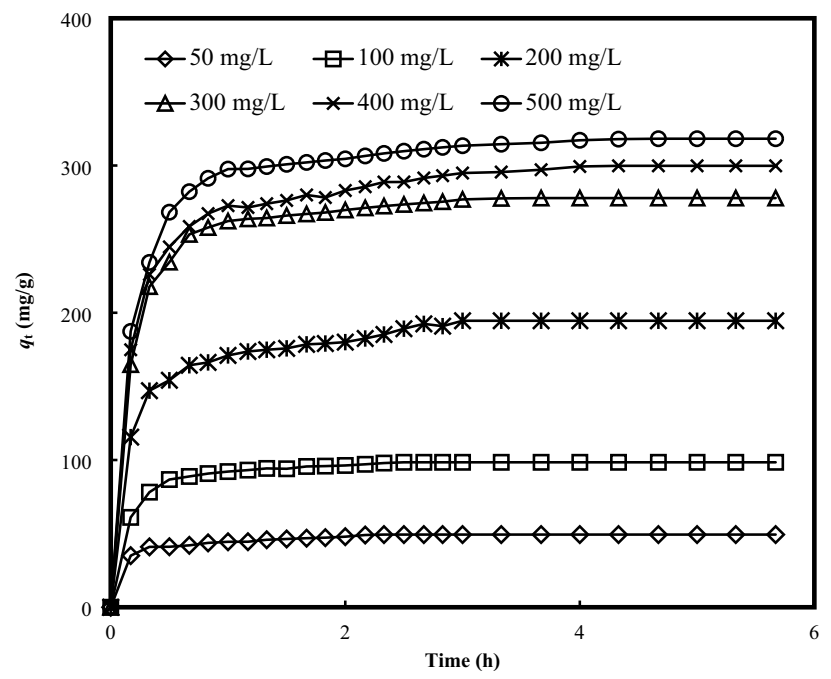

Figure 2. Effect of initial concentrations and contact time on the adsorptive uptake of $\mathrm{MB}$ onto BB (Adsorbent dosage $=0.2 \mathrm{~g} / 200 \mathrm{~mL}$; Temperature $=30^{\circ} \mathrm{C}$; Initial concentration $=50-500 \mathrm{mg} / \mathrm{L}$ ).

from 1:1 to 1:3 indicated a steadily rise of the adsorption uptake from 205.67 to $252.59 \mathrm{mg} / \mathrm{g}$, with the best IR recorded at 1:3. The phenomena may be ascribed to the rising ionic force with the incorporation of sodium salt into the clay structure, that has induced a double layer compression to assist the process of approximation and association of the clay structure. Therefore, the dye molecules which were initially bonded as the aggregates or monomers onto the external surface of the clay minerals during the association process, could be re-located into the internal region. Cione et $\mathrm{al} .{ }^{5}$ further stated that, the electrostatic repulsion between the negative charged of the clay particles would be screened in the presence of salt, that in turn reduced the repulsive interaction, favouring the approximation between the tactoids, resulting in the entrapment of $\mathrm{MB}$ as the monomers or aggregates molecules.

In contrast, the subsequent increase in the IR ratio, beyond the optimum value showed a gradually decrease in the adsorptive uptake of MB. The excessive presence of sodium salt would promote vigorous reaction within the clay particles, which destroyed the clay framework, resulting in a dramatic reduction of the accessible surface binding sites. The adsorption mechanism, which has been reported to occur partly by ion exchange releasing cations in the interlayer and basal plane surfaces, and partially via non-columbic interaction between the bentonite surface neutralized site and the adsorbed cation, is greatly governed by the changing surface polarity, compression layer, or ionic strength of the negatively charged adsorbent. In this sense, the excessive deposition of sodium would introduce a repulsive force to the cationic MB molecules, resulting in the reduction of the adsorptive uptake.

Effect of initial concentration and contact time. The effect of initial concentration and contact time for the adsorptive uptake of $\mathrm{MB}$ onto $\mathrm{BB}$ at $30^{\circ} \mathrm{C}$ is displayed in Fig. 2. It could be observed that the adsorption process increased rapidly at the initial time intervals, before the transitional phase took place, and reached to a plateau. At the initial stage, the adsorption uptake rate increased significantly, signalling the presence of readily accessible surface binding sites ${ }^{22}$. As the equilibrium approached, the process turned slower, where the maximum adsorptive uptake under the operating conditions reflects the equilibrium uptake. From the present result, it can be inferred that the rising adsorptive uptake from 49 to $318 \mathrm{mg} / \mathrm{g}$ with the increasing initial MB concentration from 50 to $500 \mathrm{mg} / \mathrm{L}$, may ascribed to a higher concentration gradient to overcome the mass transfer resistance between the aqueous MB solution and the solid BB.

Furthermore, in the MB-BB suspension system, the adsorptive uptake of MB dye molecules to the external surface of $\mathrm{BB}$ would result in the rising local concentration of $\mathrm{MB}$ dye, with the formation of dye aggregates ${ }^{23}$. These MB molecules would further migrate to the interlamellar region, with the disaggregation of MB aggregates, and restoration of the $\mathrm{MB}$ monomers ${ }^{24}$. At the higher loading of $\mathrm{MB}$, these agglomerates of dye molecules are predicted to be dominant, while these monomers or dimers would be practically absent in the MB-BB complexes. Additionally, it can be found that a longer contact time was required for a higher $\mathrm{MB}$ concentration to attain the equilibrium. The obtained findings could be depicted by the diffusion of MB molecules across the boundary layer, into the internal structure of adsorbent, and to the binding sites ${ }^{25}$, suggested a smooth and monolayer coverage of $\mathrm{MB}$ dye onto $\mathrm{BB}$.

Effect of solution $\mathrm{pH}$. The changing solution $\mathrm{pH}$ remains one of the most influencing parameters determining the performance of the adsorption process. The response is particularly due to influence of the hydrogen ions which may affect the surface charges and ionization of the functionalities of the solid adsorbent ${ }^{26}$. Figure 3 shows the changing adsorptive uptake of $\mathrm{MB}$ onto $\mathrm{BB}$ as a function of solution $\mathrm{pH}$. In the aqueous medium, cationic dye including $\mathrm{MB}$ tend to produce the reduced form of $\mathrm{CH}^{+}$and $\mathrm{C}^{+}$cations ${ }^{27}$. The negatively surface 


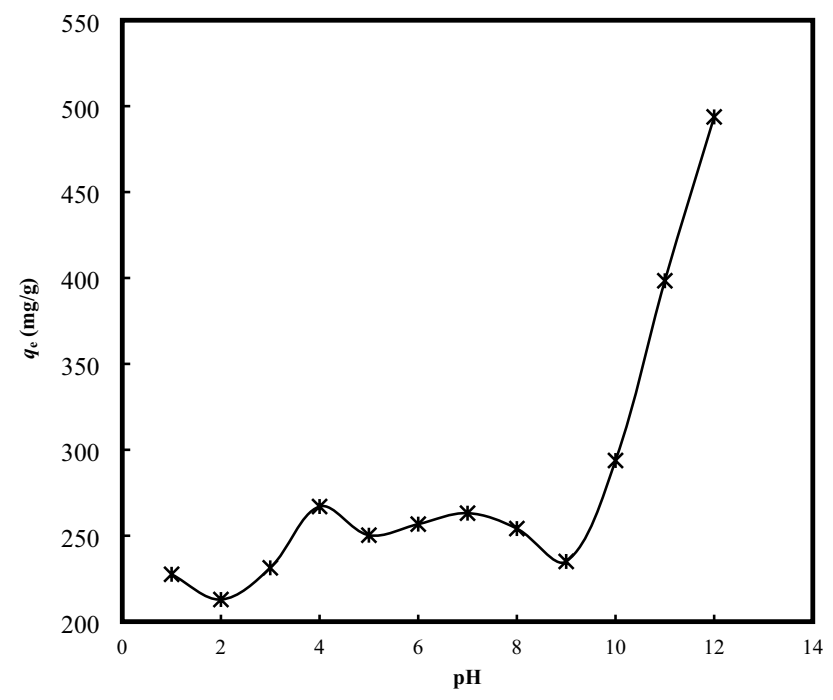

Figure 3. Effect of solution $\mathrm{pH}$ on the adsorptive uptake of $\mathrm{MB}$ onto $\mathrm{BB}$ (Adsorbent dosage $=0.2 \mathrm{~g} / 200 \mathrm{~mL}$; Temperature $=30^{\circ} \mathrm{C}$; Initial concentration $=500 \mathrm{mg} / \mathrm{L}$ ).

charged surface binding sites within the clay based adsorbent would favor the adsorption of the cationic MB dye, driven by the electrostatic attraction force. Lowering the $\mathrm{pH}$ range would generate a positive charged or protonated surface on the clay adsorbent, with a dramatic electrostatic repulsion effect hindering the adsorptive interaction, and further amplified by the competing effect between the dye cations and the effect of excess $\mathrm{H}^{+}$ ions for the surface binding sites ${ }^{28}$. On the other hand, the higher $\mathrm{pH}$ values within the basic medium would induce a negative charge to the surface $\mathrm{BB}$, in strengthening the electrostatic interactions between the cationic $\mathrm{MB}$ and the negatively charged $\mathrm{BB}^{29}$. With the $\mathrm{pH}_{\mathrm{zpc}}$ of 9 , the $\mathrm{BB}$ surface turned positive at the $\mathrm{pH}$ below 9 , and showed a net negative charge at the $\mathrm{pH}$ above the $\mathrm{pH}_{\mathrm{zpc}}$, which supported the adsorption of cationic $\mathrm{MB}$ onto the negatively charged BB via electrostatic attraction after the modification process as described in Eq. (21).

$$
\mathrm{BB}^{-} \mathrm{SiO}^{-}+\mathrm{MB}^{+} \leftrightarrow \mathrm{BB}-\mathrm{SiO}^{-}--{ }^{+} \mathrm{MB}
$$

Specifically, the potential surface charge of the clay-aqueous system is mainly governed by the activity of the ions or the newly formed ion complex with $\mathrm{H}^{+}$and $\mathrm{OH}^{-}$derived as:

$$
\mathrm{SiOH}+\mathrm{OH}^{-} \rightarrow \mathrm{SiOH}^{-}+\mathrm{H}_{2} \mathrm{O}
$$

In this study, the maximum adsorptive uptake of $\mathrm{MB}$ onto $\mathrm{BB}$ was found to be at the basic medium, where an extremely high cation exchange capacity was recorded, and driven by the basal oxygen surface of the tetrahedral sheets with the MB solution, which contain excess hydroxyl ion. The highly saline solution at the alkaline environment was expected to contribute to the protonation/deprotonation of the surface hydroxy site $(\mathrm{M}-\mathrm{OH})$, not limited to the alumina group of the $\mathrm{BB}$, which gave rise to the more negative charges.

$$
\mathrm{H}_{2} \mathrm{O}+\mathrm{M}-\mathrm{O}^{-} \underset{\mathrm{OH}^{-}}{\stackrel{\mathrm{H}^{+}}{\longrightarrow}} \mathrm{M}-\mathrm{H} \underset{\mathrm{OH}^{-}}{\stackrel{\mathrm{H}^{+}}{\longrightarrow}} \mathrm{M}-\mathrm{OH}_{2}^{+}
$$

These potential determining ions are represented by $\mathrm{H}^{+}$and $\mathrm{OH}^{-}$, and this aforementioned electrostatic force between of the negatively charged $\mathrm{BB}$ and the positively charged $\mathrm{MB}$ would result in a greater uptake of cationic dyes.

Isotherm modelling. The modelling is the development of representative equation of the adsorption system, which could be applied for the design purposes ${ }^{30}$. It is well known that, the estimation of isotherm parameters from the non-linear isotherm modelling is preferred in minimizing the data distribution errors between the experimental and predicted parameters or fit distortions of the linearization models ${ }^{31}$. Three non-linear equilibrium isotherms, specifically Langmuir, Freundlich, and Temkin isotherms have been adopted. Each theoretical plots of the modelling have correlated with the experimental data, and further evaluated by the correlation coefficients $\left(R^{2}\right)$ and Root Mean Square Deviation $(R M S D)$. The isotherm parameters with the correlation $R^{2}$ and $R M S D$ are tabulated in Table 1 . The presented data was most suitable described by the Langmuir isotherm, with the highest $R^{2}$ value of 0.998 , and the lowest $R M S D$ value of 1.70 . The best fit to the Langmuir isotherm model suggested the homogeneous nature, energetically equivalent and identical of the surface binding sites, with the corresponding $Q_{0}$ and $K_{\mathrm{L}}$ of $318.38 \mathrm{mg} / \mathrm{g}$ and $0.29 \mathrm{~L} / \mathrm{mg}$, respectively.

The equilibrium data was further analyzed with respect to the separation factor $\left(R_{\mathrm{L}}\right)$, a dimensionless constant proposed by: 


\begin{tabular}{|l|l|c|}
\hline Isotherm & Parameter constants & \\
\hline \multirow{5}{*}{ Langmuir } & $Q_{0}(\mathrm{mg} / \mathrm{g})$ & 318.38 \\
\cline { 2 - 3 } & $K_{\mathrm{L}}(\mathrm{L} / \mathrm{mg})$ & 0.29 \\
\cline { 2 - 3 } & $R^{2}$ & 0.998 \\
\cline { 2 - 3 } & $R M S D$ & 1.70 \\
\hline \multirow{5}{*}{ Freundlich } & $K_{\mathrm{F}}\left((\mathrm{mg} / \mathrm{g})(\mathrm{L} / \mathrm{mg})^{1 / \mathrm{n}}\right)$ & 112.43 \\
\cline { 2 - 3 } & $n$ & 4.65 \\
\cline { 2 - 3 } & $R^{2}$ & 0.827 \\
\cline { 2 - 3 } & $R M S D$ & 15.53 \\
\hline \multirow{5}{*}{ Temkin } & $\mathrm{A}(\mathrm{L} / \mathrm{g})$ & 6.33 \\
\cline { 2 - 3 } & $B$ & 48.23 \\
\cline { 2 - 3 } & $R^{2}$ & 0.949 \\
\cline { 2 - 3 } & $R M S D$ & 9.46 \\
\hline
\end{tabular}

Table 1. Adsorption isotherm parameters for the adsorption of $\mathrm{MB}$ onto $\mathrm{BB}$ at $30^{\circ} \mathrm{C}$.

\begin{tabular}{|c|c|c|c|c|}
\hline Clay & Activation method & Activating agent & $\begin{array}{l}\text { Monolayer adsorption } \\
\text { capacity, }(\mathrm{mg} / \mathrm{g})\end{array}$ & References \\
\hline Bentonite & Low temperature & $\mathrm{NaCl}$ & 318 & Present study \\
\hline Bentonite & Ion exchange & $\begin{array}{l}\text { Hexadecyltrimenthylammo- } \\
\text { nium chloride }\end{array}$ & 1 & $\begin{array}{l}\text { Anirudhan and } \\
\text { Ramachandran }^{32}\end{array}$ \\
\hline Palygorskite & Ion exchange & $\mathrm{NaOH}$ & 136 & Wang et al. ${ }^{33}$ \\
\hline Bentonite & Crosslinked & Chitosan & 97 & Bulut and Karaer ${ }^{34}$ \\
\hline Montmorillonite & Pillaring & Iron oxide & 69 & Cottet et al. ${ }^{35}$ \\
\hline Montmorillonite & Ion exchange & dodecyl sulfobetaine & 150 & Fan et al. ${ }^{36}$ \\
\hline Bentonite & High pressure & Attapulgite & 110 & Liu et al. ${ }^{37}$ \\
\hline Rectorite & Ion exchange & Gemini surfactant (organic) & 46 & Zeng et al. ${ }^{38}$ \\
\hline Bentonite & Heat treatment & $\mathrm{H}_{2} \mathrm{SO}_{4}$ & 111 & Banat et al. ${ }^{39}$ \\
\hline kaolin & Calcination + Ion exchange & $\mathrm{NaOH}$ & 17 & Ghosh and Bhattacharyya ${ }^{40}$ \\
\hline Montmorillonite & Microwave irradiation & Sulfonated chitosan & 188 & Abdul Mubarak et al. ${ }^{41}$ \\
\hline
\end{tabular}

Table 2. Comparative evaluation of monolayer adsorption capacities for MB onto different clay derivatives.

$$
R_{\mathrm{L}}=\frac{1}{1+K_{\mathrm{L}} C_{0}}
$$

whereby $R_{\mathrm{L}}$ is a quantitative verification on the favourability of the adsorption system where $R_{\mathrm{L}}=0$ indicates irreversible, $0<R_{\mathrm{L}}<1$ represents favorable, $R_{\mathrm{L}}=1$ is linear and $R_{\mathrm{L}}>1$ corresponds to unfavourable interaction. From Supplemental Fig. S1, it has been found that the calculated $R_{\mathrm{L}}$ ranged between 0.01 and 0.1 at the initial concentration range of 50-500 mg/L, indicating favourable of the tested adsorption system. Table $2^{32-41}$ shows a comparative evaluation of the monolayer adsorption capacity for MB onto different functionalized clay based adsorbent. The clay based adsorbent reported in this research showed a relatively greater performance as compared with the reported literature findings.

Adsorption kinetics and mechanism study. Adsorption kinetic represents a variable tool elucidating the residence time and controlling step of the adsorptive interaction. The equilibrium data was simulated by pseudo-first order, pseudo-second order and Elovich kinetic equations by adopting the linear plots of $\ln \left(q_{\mathrm{e}}-q_{\mathrm{t}}\right)$ against $t, t / q_{\mathrm{t}}$ versus $t$, and $q_{\mathrm{t}}$ against $\ln t$, respectively. The adsorption data given in Supplemental Table S1 showed a good compliance with the pseudo-second order equation, with the highest $R^{2}$ and lowest $\Delta q$ (\%) of 0.999 and $1.08-5.32 \%$, respectively. This suggested that chemisorption may be the rate-limiting step, with electrons sharing between $\mathrm{MB}$ cations and the hydrophilic site of BB. However, the experimental $q_{\mathrm{e}}$ results were deviated significantly from the theoretical value with the pseudo-first order and Elovich kinetic models, implying more than one-step may be involved in the adsorption MB molecules onto BB. Similar correlation has been recorded by previous researches for the adsorption of $\mathrm{MB}$ dye onto different functionalized adsorbents ${ }^{23,42}$.

The diffusion mechanism was further accessed using the Weber and Morris ${ }^{18}$ intraparticle diffusion model, which describes the time-dependent diffusion of adsorbate components of the adsorption process. The model implies that particle diffusion is the controlling step if the relationship between the adsorbed adsorbate per unit mass of adsorbent $\left(q_{\mathrm{t}}\right)$ versus the square root of time $\left(t^{1 / 2}\right)$ provide a straight line, and passes through the origin ${ }^{43}$. Specifically, external diffusion, surface diffusion or pore diffusion have been identified to be the major steps, driven by the ion exchange, complexation, precipitation or a combination of their interactions ${ }^{44}$. 


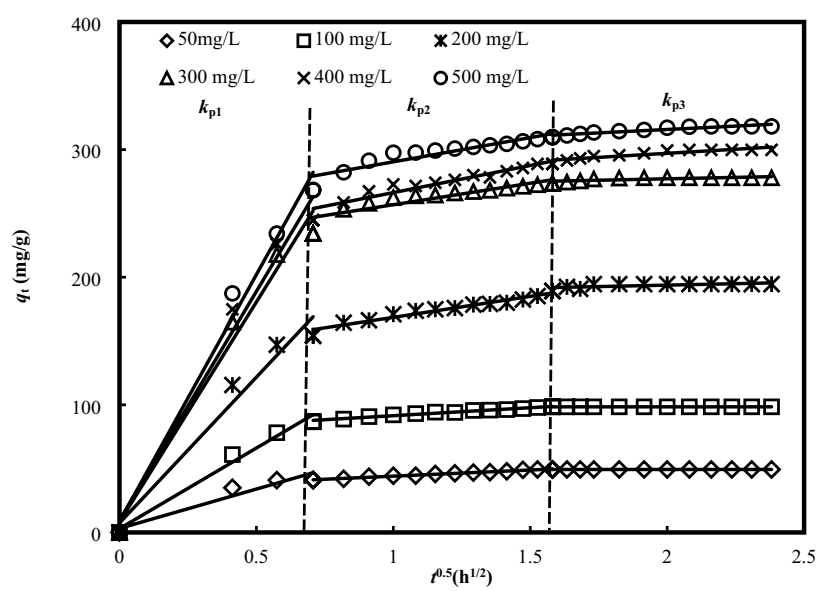

(a)

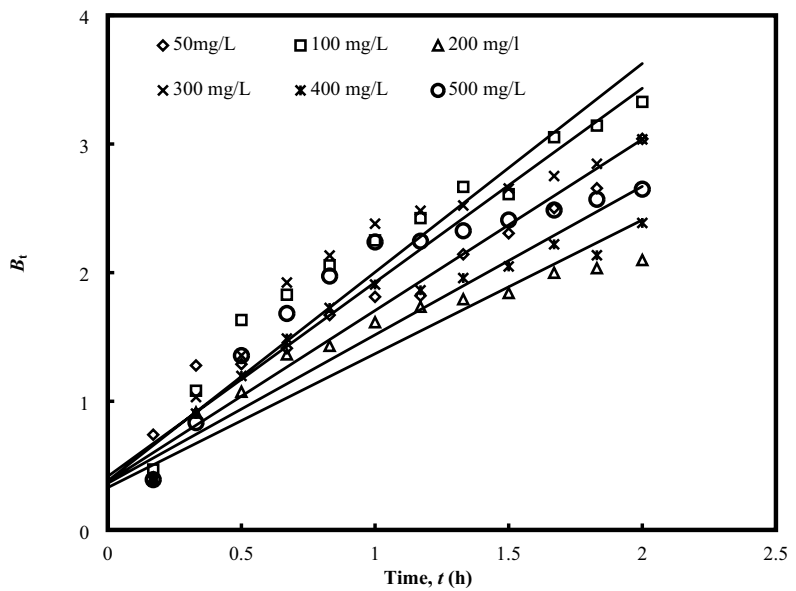

(b)

Figure 4. Intraparticle diffusion (a) and Boyd plots models (b) for the adsorption of $\mathrm{MB}$ onto $\mathrm{BB}$ at $30^{\circ} \mathrm{C}$.

The instantaneous adsorption of the first $40 \mathrm{~min}$ may be corresponded to the mass transfer of adsorbate molecules from the bulk solution onto the adsorbent surface, subsequent by gradual adsorption stage of the external mass transfer resistance, that was mainly intraparticle diffusion controlled. The alteration is related to the coupling between solid and liquid phases, or the initial and boundary of the interactive system ${ }^{45}$. The final equilibrium stage is the last stage, where the adsorption process started to slow down, and reached to a plateau. From the presented findings, the greater adsorption rate was observed at the initial stage, and it reduced gradually as the equilibrium approached. This changing equilibrium behaviour could be resulted from the dimerization of the $\mathrm{MB}$ molecules at the higher initial concentration range or ionization of the $\mathrm{MB}$ molecules, with one or more reactions took place during the adsorption interaction ${ }^{28}$.

The results summarized in Supplemental Table S2 provide good agreement that intraparticle diffusion represents the rate controlling step of the adsorption process, supported by the plots $q_{\mathrm{t}}$ versus $t^{1 / 2}$ plots (Fig. 4a) that moved beyond the origin, and the linear straight lines yields the intercepts $C_{\mathrm{i}}$. This intercept $C_{\mathrm{i}}$ reveals the growing thickness of the boundary layer, with larger the $C_{\mathrm{i}}$ value, indicates the greater effect ${ }^{46}$. If the diffusion could be identified, the boundary layer may be seen as a viscous drag between the adsorbate and BB over the bulk surface, and the higher adsorptive uptakes could be represented by the rising $C_{\mathrm{i}}$ values.

The experimental data were further fitted to the Boyde's equation ${ }^{47}$ for predicting the rate controlling phase of the adsorption process. Accordingly, the rate limiting step is film-diffusion or chemical reaction controlled if the plot is linear or non-linear, but do not pass through the origin. Conversely, intraparticle diffusion is the rate controlling step if a straight line passes through the origin is produced. As demonstrated by Fig. $4 \mathrm{~b}$, the plots with a linear profile but did not pass through the origin, verified that external transport to be the major rate limiting step, due to the major governance by film diffusion, and external transports at the surface could be more prominent than the internal transport, with the assumption that the controlling mechanism at the surface of $\mathrm{BB}$ was a result of the chemical interaction.

Thermodynamic study. The energy change in term of thermodynamic consideration represents an important marker for the practical application, and provides additional knowledge underlying the inherent energetic 


\begin{tabular}{|c|c|c|c|c|}
\hline \multicolumn{3}{|c|}{$\Delta G^{\circ}(\mathbf{k J} / \mathrm{mole})$} & \multirow[b]{2}{*}{$\Delta H^{\circ}(\mathrm{kJ} / \mathrm{mole})$} & \multirow[b]{2}{*}{$\Delta S^{\circ}(\mathrm{J} /$ mole $K)$} \\
\hline $303 \mathrm{~K}$ & $313 \mathrm{~K}$ & $323 \mathrm{~K}$ & & \\
\hline-6.38 & -7.77 & -9.58 & 42.04 & 159.55 \\
\hline
\end{tabular}

Table 3. Thermodynamic parameters for the adsorption of $\mathrm{MB}$ onto $\mathrm{BB}$.

different during the adsorptive interaction ${ }^{48}$. The Gibbs free energy change, $\Delta G^{\circ}$, indicates the spontaneity of a reaction and therefore justifies the viability of the adsorptive system. The $\Delta G^{\circ}$ for the adsorption system at the tested temperature range were computed by Eq. (20), as depicted in Table 3. Increasing the adsorption temperature from 30 to $50{ }^{\circ} \mathrm{C}$, recorded a steadily decrease of $\Delta G^{\circ}$ from -6.38 to $-9.58 \mathrm{~kJ} / \mathrm{mol}$, illustrating greater feasibility of the adsorption at the higher temperature range, indicative of spontaneous nature and low activation energy of the adsorptive interaction. The results were supported by the rising $Q_{0}$ from 318.38 to $357.14 \mathrm{mg} / \mathrm{g}$. At the low temperatures region, the competition between the $\mathrm{MB}$ and water molecules took place within the interlamellar surface, resulted from the strong hydrophilic feature of the clay layer, and an intensive electrostatically interaction. In this sense, the high charged trimmers $\left(\mathrm{MB}^{+}\right)_{3}$ may involve in ion pairing mechanism for the intensive interaction surface within the active sites of the clay minerals at the low temperature region. The rising temperature however could facilitate the formation of well-defined adsorbed molecules around the exchange sites, driven by delamination of the clay particles, mainly attributed to the greater interactions and changing swelling properties of the bentonite surface.

The physical or chemical interactions depends on the magnitude of $\Delta G^{\circ}$, in which $-20 \mathrm{~kJ} / \mathrm{mole}$ corresponded to the spontaneous physical processes, and the $\Delta G^{\circ}$ between -80 to $-400 \mathrm{~kJ} / \mathrm{mole}$ is denoted to the chemisorption process ${ }^{30}$. The acquired $\Delta G^{\circ}$ for the adsorption system ranging from -6.38 to $-9.58 \mathrm{~kJ} / \mathrm{mole}$, revealed that it is dominated primarily by the physical adsorption mechanism. This similar trend has been supported by Alhumaimess ${ }^{49}$, Oukil et al. ${ }^{50}$, and Uyar et al. ${ }^{51}$ for the adsorption of MB onto vermiculate, modified HUSY zeolite and an amorphous mixture of $\gamma$-alumina and silica, and alginate-clay quasi-cryogel beads, respectively. The values of $\Delta S^{\circ}$ derived from the plot of $\Delta G^{\circ}$ versus $T$ was found to be $159.55 \mathrm{~J} / \mathrm{mole} K$. The positive standard entropy $\left(\Delta S^{\circ}\right)$ may be related to the hydration of dye cations, reorientation, and restructuring of the clay platelets, and rocketed the high affinity of BB for MB molecules, with structural changes in dyes and BB surface ${ }^{52}$. This positive entropy change was ascribed to the increasing disorder, driven by the delamination of $\mathrm{BB}$, with the formation of an ordered system.

Morphological structure and surface characteristics. The fundamental physical properties and morphological structure of the functionalized adsorbents was accessed in term of Scanning Electron Microscopy (SEM), as presented in Fig. 5. The smooth appearance of the raw bentonite surface could be closely related to the packed flakes structures. In contrast, BB demonstrated a well developed meso and microstructural porosity. The incorporation of accumulated sodium salt crystals implied a detrimental effect on bentonite structure, to generate a siliceous skeleton with wide quantity of open-air voids, characterized by a broad range of mutual bonds and interfacial zones. The smectite leaflets have been completely de-structured after the chemical modification, with the collapse of the interlayer spaces within the raw bentonite.

The FTIR spectra of the raw bentonite and BB are given in Supplemental Fig. S2. The detected OH stretching of the adsorbed water could be observed within the multiple broad band of $3400-3650 \mathrm{~cm}^{-1}$, implied the presence of two types of $\mathrm{OH}$ groups related to the hydrogen bonding and isolated $\mathrm{OH}$-group. The shifted from 3622 to $3624 \mathrm{~cm}^{-1}$, and $3429 \mathrm{~cm}^{-1}$ to $3436 \mathrm{~cm}^{-1}$ of adsorption band after the modification could be attributed to the structural $\mathrm{OH}$ groups of $\mathrm{BB}$. The aliphatic hydrocarbons of the raw bentonite is ascribed to the sharp peaks at $2925 \mathrm{~cm}^{-1}$ and $1431-1433 \mathrm{~cm}^{-153}$, while the $\mathrm{OH}$ group and $\mathrm{Al}-\mathrm{Al}-\mathrm{OH}$ bending resulting from the dioctahedral montmorillonite 2:1 layer were detected at $1638-1639 \mathrm{~cm}^{-1}$ and $916 / 917 \mathrm{~cm}^{-154}$. The strong absorption band at $1035 \mathrm{~cm}^{-1}$ and the sharp peak at $796-797 \mathrm{~cm}^{-1}$ are due to the $\mathrm{Si}-\mathrm{O}$, and the quartz admixture of the clay based-adsorbent, while the intensity at $695-694 \mathrm{~cm}^{-1}$ is driven by the deformation of the $\mathrm{Si}-\mathrm{O}$ bond. The tetrahedral bending modes of $\mathrm{Si}-\mathrm{O}-\mathrm{Al}$ and $\mathrm{Si}-\mathrm{O}-\mathrm{Si}$ could be illustrated at 523 and $466-467 \mathrm{~cm}^{-1}$. From the presented analysis, the substitution of the sodium salt of the raw metal ions in the interlayer clay structure, or located into the $\mathrm{Si}-\mathrm{O}$ sheets hexagonal cavities induced changes in the $\mathrm{Si}-\mathrm{O}$ vibration modes of the bentonite have led to the reconstruction of the tetrahedral sheets either in the hexagonal holes, or in the previously vacant octahedral sites. The result was supported by Jawad and Abdulhameed ${ }^{55}$, who reported the potential of silanol $(\equiv \mathrm{SiOH})$, aluminol $(\equiv \mathrm{AlOH}$, and hydroxyl $(-\mathrm{OH})$ groups as the potential active sites within the mineral edges. Accordingly, electrostatic attraction is considered to be one of the most impactful interaction between the MB dye molecules with the clay based adsorbent. Other governing mechanisms for sorption process are $\mathrm{H}$-bonding between the $\mathrm{H}$ atom available on the surface of $\mathrm{BB}$, and the $\mathrm{N}$ within atom in the MB dye structure, and $n-\pi$ between the delocalization of the lone pair electron of $\mathrm{O}$ atoms into the $\pi$ orbital of the dye aromatic rings ${ }^{56}$.

Impenetrability of nitrogen to the interlayer space of clay minerals represents an appropriate method in describing the chemical transformation of the external surface of the functionalized materials. The detailed of porosity structures of the raw bentonite and BB are summarized in Supplemental Table S3. It was evident that a greater porosity development was found at BB, with the higher BET surfaces area of $426.91 \mathrm{~m}^{2} / \mathrm{g}$, Langmuir surface area of $539.02 \mathrm{~m}^{2} / \mathrm{g}$, and total pore volume of $0.225 \mathrm{~cm}^{3} / \mathrm{g}$, respectively, as compared with the raw bentonite. The greater porosity structure could be ascribed to the considerable amount of trapped pores in the range of micro and medium mesopores (20-400 $\AA$ ) of $\mathrm{BB}$, and this ion valence behaviour is expected to be more important in improving the textural properties of the clay derivatives ${ }^{57}$. The porosity development is interrelated to the 


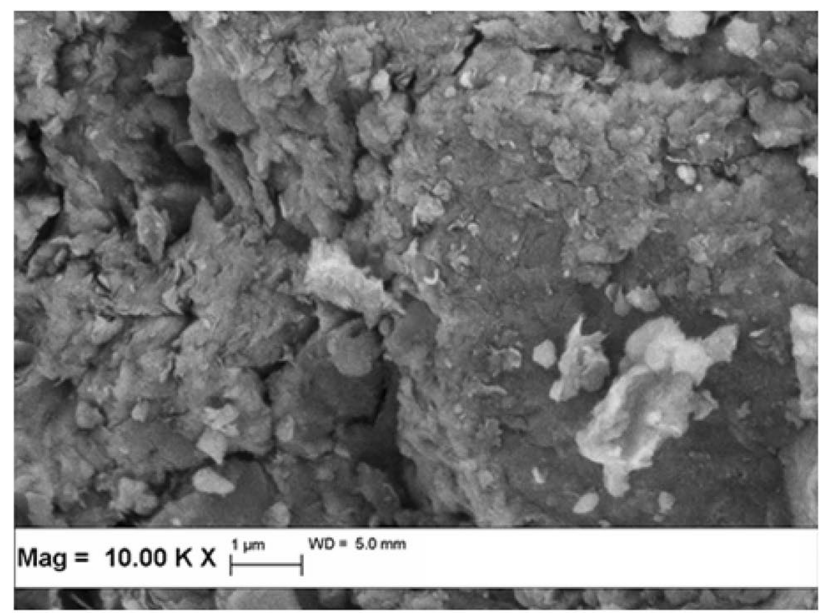

(a)

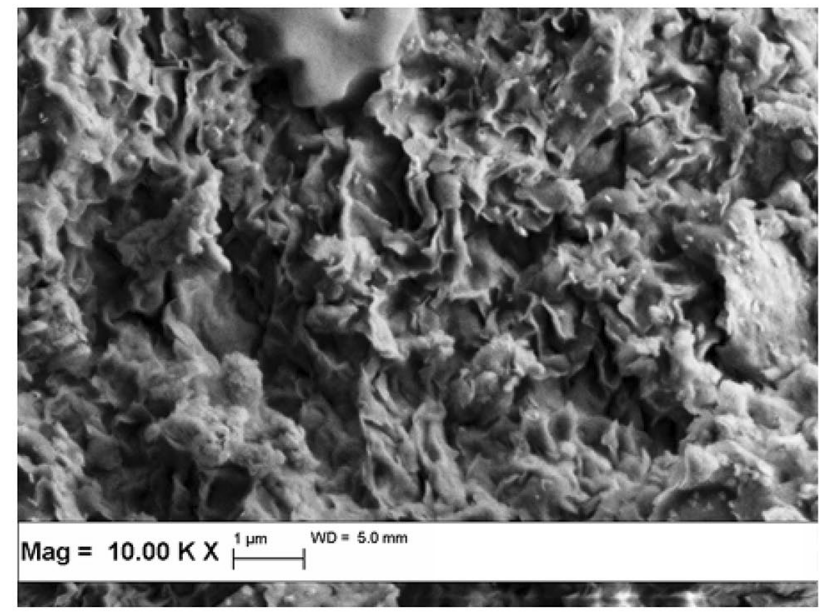

(b)

Figure 5. Scanning electron micrographs of (a) bentonite and (b) BB.

stacking level of different elementary layers, to support the formation of outer sphere and adsorption process. The intercalation of the $\mathrm{Na}^{+}$cations during the modification has reduced the number of macropores and large mesopores (> $400 \AA ̊)$, resulting in the dramatic improvement of the textural properties of the raw bentonite. Pore size distribution (PSD) is a model of adsorbent internal structure, elucidating the complex void spaces within the functionalized adsorbent, and the fraction of pore surface of a given shape and size. It is classified into micropores $(\mathrm{d}<2 \mathrm{~nm})$, mesopore $(\mathrm{d}=2-50 \mathrm{~nm})$ and macropore $(\mathrm{d}>50 \mathrm{~nm})$ according to the classification of International Union of Pure and Applied Chemistry (IUPAC) pore dimensions. From the presented pore size given in Supplemental Fig. S3 justified by the Density Functional Theory model, intensive peaks of the pore diameter (40-70 ̊) were detected at a vast majority of the mesoporous region, which are capable to support the overall adsorption process. The rising pore volume under $\mathrm{NaCl}$ treatment could be driven by the production of finely scattered $\mathrm{Si}$ oxides, destruction and leaching of ion mineral, removal of silica compound or X-ray amorphous aluminium, blocking the interlamellar spaces and surface porosity by the voids, cracks or decrease in the mineral particle sizes, in which a larger proportion of the newly formed surfaces may be connected to new pore walls.

\section{Conclusion}

In this work, the sodium salt induced activation of bentonite derived adsorbent at low temperature has been attempted. The specific surface area, and total pore volume was identified to be $426.91 \mathrm{~m}^{2} / \mathrm{g}$ and $0.225 \mathrm{~cm}^{3} / \mathrm{g}$, respectively. Adopting methylene blue as the model adsorbate, the best chemical impregnation ratio at 1:3 resulted in a monolayer adsorption capacity of $318.38 \mathrm{mg} / \mathrm{g}$, well described by the Langmuir isotherm and pseudo-second order kinetic equations. The adsorption process was feasible, endothermic and spontaneous in nature, supported by different surface active sites, notably silanol, aluminol, and hydroxyl groups. The presented results provide a new insight into the sodium salt assisted activation of high-quality clay-based adsorbents, with a reliable, simple, efficient and economical approach. 
Received: 5 November 2021; Accepted: 21 January 2022

Published online: 15 February 2022

\section{References}

1. Mi, J., Gregorich, E. G., Xu, S., McLaughlin, N. B. \& Liu, J. Effect of bentonite as a soil amendment on field water-holding capacity, and millet photosynthesis and grain quality. Sci. Rep. 10, 1-12 (2020).

2. Shattar, S. F. A., Zakaria, N. A. \& Foo, K. Y. Enhancement of hazardous pesticide uptake, ametryn using an environmentally friendly clay-based adsorbent. Desalin. Water Treat. 79, 1-8 (2017).

3. Özcan, A. S. \& Özcan, A. Adsorption of acid dyes from aqueous solutions onto acid-activated bentonite. J. Colloid Interface Sci. 276, 39-46 (2004).

4. Sarkar, B. et al. Bioreactive organoclay: A new technology for environmental remediation. Crit. Rev. Environ. Sci. Technol. 42, 435-488 (2012).

5. Cione, A. P. P., Schmitt, C. C., Neumann, M. G. \& Gessner, F. The effect of added salt on the aggregation of clay particles. J. Colloid Interface Sci. 226, 205-209 (2000).

6. Bouras, O., Bollinger, J. C., Baudu, M. \& Khalaf, H. Adsorption of diuron and its degradation products from aqueous solution by surfactant-modified pillared clays. Appl. Clay Sci. 37, 240-250 (2007).

7. Leodopoulos, C., Doulia, D. \& Gimouhopoulos, K. Adsorption of cationic dyes onto bentonite. Sep. Purif. Rev. 44, 74-107 (2015).

8. Pentrák, M., Czímerová, A., Madejová, J. \& Komadel, P. Changes in layer charge of clay minerals upon acid treatment as obtained from their interactions with methylene blue. Appl. Clay Sci. 55, 100-107 (2012).

9. Kaufhold, S. \& Dohrmann, R. Stability of bentonites in salt solutions | sodium chloride. Appl. Clay Sci. 45, 171-177 (2009).

10. Stawiński, W. et al. Simultaneous removal of dyes and metal cations using an acid, acid-base Reader.pdf. Sci. Total Environ. 576, 398-408 (2017).

11. Shattar, S. F. A., Zakaria, N. A. \& Foo, K. Y. One step acid activation of bentonite derived adsorbent for the effective remediation of the new generation of industrial pesticides. Sci. Rep. 10, 1-13 (2020).

12. Langmuir, I. The adsorption of gases on plane surfaces of glass, mica and platinum. J. Am. Chem. Soc. 40, 1361-1403 (1918).

13. Freundlich, H. M. F. Over the adsorption in solution. J. Phys. Chem. 57, 385-471 (1906).

14. Temkin, M. I. \& Pyzhev, V. Kinetics of ammonia synthesis on promoted iron catalysts. Acta Physicochim. URSS 12, 327-356 (1940).

15. Lagergren, S. \& Svenska, B. K. Zur theorie der sogenannten adsorption gelöester stoffe. Veternskapsakad Handl. 24, 1-39 (1898).

16. Ho, Y. S. \& McKay, G. The Kinetics of sorption of basic dyes from aqueous solution by Sphagnum moos peat. Can. J. Chem. Eng. 76, 822-827 (1998).

17. Aharoni, C. \& Tompkins, F. C. C. Kinetics of adsorption and desorption and the Elovich equation. In Advances in Catalysis and Related Subjects (eds Eley, D. D. et al.) 1-49 (Academic Press, 1970).

18. Weber, W. J. \& Morris, J. C. Kinetics of adsorption on carbon from solutions. J. Sanit. Eng. Div. Am. Soc. Civ. Eng. 89, 31-60 (1963).

19. Boyd, G. E., Schubert, J. \& Adamson, A. W. The exchange adsorption of ions from aqueous solutions by organic zeolites. I. kinetics. J. Am. Chem. Soc. 69, 2818-2829 (1947).

20. Shattar, S. F. A., Zakaria, N. A. \& Foo, K. Y. Preparation of a montmorillonite-derived adsorbent for the practical treatment of ionic and nonionic pesticides. J. Mater. Res. Technol. 8, 4713-4724 (2019).

21. Ho, Y. S., Chiang, T. H. \& Hsueh, Y. M. Removal of basic dye from aqueous solution using tree fern as a biosorbent. Process. Biochem. 40, 119-124 (2005).

22. Wang, Y., Zhou, Y., Jiang, G., Chen, P. \& Chen, Z. One-step fabrication of carbonaceous adsorbent from corncob for enhancing adsorption capability of methylene blue removal. Sci. Rep. 10, 1-9 (2020).

23. Gürses, A. et al. The adsorption kinetics of the cationic dye, methylene blue, onto clay. J. Hazard. Mater. 131, 217-228 (2006).

24. Neumann, M. G., Gessner, F., Schmitt, C. C. \& Sartori, R. Influence of the layer charge and clay particle size on the interactions between the cationic dye methylene blue and clays in an aqueous suspension. J. Colloid Interface Sci. 255, 254-259 (2002).

25. Gao, D. W., Tao, Y., An, R., Fu, Y. \& Ren, N. Q. Fate of organic carbon in UAFB treating raw sewage: Impact of moderate to low temperature. Bioresour. Technol. 102, 2248-2254 (2011).

26. Al-Ghouti, M. A. \& Al-Absi, R. S. Mechanistic understanding of the adsorption and thermodynamic aspects of cationic methylene blue dye onto cellulosic olive stones biomass from wastewater. Sci. Rep. 10, 1-18 (2020).

27. Kavitha, D. \& Namasivayam, C. Experimental and kinetic studies on methylene blue adsorption by coir pith carbon. Bioresour. Technol. 98, 14-21 (2007).

28. Almeida, C. A. P., Debacher, N. A., Downs, A. J., Cottet, L. \& Mello, C. A. D. Removal of methylene blue from colored effluents by adsorption on montmorillonite clay. J. Colloid Interface Sci. 332, 46-53 (2009).

29. Eltaweil, A. S., Mamdouh, I. M., Abd El-Monaem, E. M. \& El-Subruiti, G. M. Highly efficient removal for methylene blue and Cu ${ }^{2+}$ onto UiO-66 metal-organic framework. ACS Omega 6, 23528-23541 (2021).

30. Foo, K. Y. \& Hameed, B. H. Insights into the modeling of adsorption isotherm systems. Chem. Eng. J. 156, 2-10 (2010).

31. Foo, K. Y. Effect of microwave regeneration on the textural network, surface chemistry and adsorptive property of the agricultural waste based activated carbons. Process. Saf. Environ. Prot. 116, 461-467 (2018).

32. Anirudhan, T. S. \& Ramachandran, M. Adsorptive removal of basic dyes from aqueous solutions by surfactant modified bentonite clay (organoclay): Kinetic and competitive adsorption isotherm. Process. Saf. Environ. Prot. 95, 215-225 (2015).

33. Wang, W., Wang, F., Kang, Y. \& Wang, A. Enhanced adsorptive removal of methylene blue from aqueous solution by alkali-activated palygorskite. Water. Air. Soil Pollut. 226, 1-13 (2015).

34. Bulut, Y. \& Karaer, H. Adsorption of methylene blue from bqueous solution by crosslinked chitosan/bentonite composite. J. Dispers. Sci. Technol. 36, 61-67 (2015).

35. Cottet, L. et al. Adsorption characteristics of montmorillonite clay modified with iron oxide with respect to methylene blue in aqueous media. Appl. Clay Sci. 95, 25-31 (2014).

36. Fan, H., Zhou, L., Jiang, X., Huang, Q. \& Lang, W. Adsorption of $\mathrm{Cu}^{2+}$ and methylene blue on dodecyl sulfobetaine surfactantmodified montmorillonite. Appl. Clay Sci. 95, 150-158 (2014).

37. Liu, Y., Kang, Y., Mu, B. \& Wang, A. Attapulgite/bentonite interactions for methylene blue adsorption characteristics from aqueous solution. Chem. Eng. J. 237, 403-410 (2014).

38. Zeng, L. et al. Study on adsorption of methylene blue with organic rectorite. Integr. Ferroelectr. 146, 29-42 (2013).

39. Banat, F., Al-Asheh, S., Al-Anbar, S. \& Al-Refaie, S. Microwave- and acid-treated bentonite as adsorbents of methylene blue from a simulated dye wastewater. Bull. Eng. Geol. Environ. 66, 53-58 (2007).

40. Ghosh, D. \& Bhattacharyya, K. G. Adsorption of methylene blue on kaolinite. Appl. Clay Sci. 20, 295-300 (2002).

41. Abdul Mubarak, N. S., Bahrudin, N. N., Jawad, A. H., Hameed, B. H. \& Sabar, S. Microwave enhanced synthesis of sulfonated chitosan-montmorillonite for effective removal of methylene blue. J. Polym. Environ. 29, 4027-4039 (2021).

42. Foo, K. Y. \& Hameed, B. H. Adsorption characteristics of industrial solid waste derived activated carbon prepared by microwave heating for methylene blue. Fuel Process. Technol. 99, 103-109 (2012).

43. Wang, Y. et al. High adsorption behavior and photoregeneration of modified graphite oxide-titanium dioxide nanocomposites for tetracycline removal in water. Process. Saf. Environ. Prot. 149, 123-134 (2021). 
44. Gerçel, Ö., Özcan, A., Özcan, A. S. \& Gerçel, H. F. Preparation of activated carbon from a renewable bio-plant of Euphorbia rigida by $\mathrm{H}_{2} \mathrm{SO}_{4}$ activation and its adsorption behavior in aqueous solutions. Appl. Surf. Sci. 253, 4843-4852 (2007).

45. Toor, M. \& Jin, B. Adsorption characteristics, isotherm, kinetics, and diffusion of modified natural bentonite for removing diazo dye. Chem. Eng. J. 187, 79-88 (2012).

46. Wang, Y., Peng, C., Padilla-Ortega, E., Robledo-Cabrera, A. \& López-Valdivieso, A. Cr(VI) adsorption on activated carbon: Mechanisms, modeling and limitations in water treatment. J. Environ. Chem. Eng. 8, 104031 (2020).

47. Boyd, G. E., Adamson, A. W. \& Myers, L. S. Jr. The exchange adsorption of ions from aqueous solutions by organic zeolites. II. kinetics. J. Am. Chem. Soc. 69, 2836-2848 (1947).

48. Shattar, S. F. A., Zakaria, N. A. \& Foo, K. Y. Utilization of montmorillonite as a refining solution for the treatment of ametryn, a second generation of pesticide. J. Environ. Chem. Eng. 5, 3235-3242 (2017).

49. Alhumaimess, M. S. Adsorption, kinetic and thermodynamic studies of safranin and methylene blue on a novel adsorbent based on phosphorylated sawdust. Desalin. Water Treat. 151, 199-211 (2019).

50. Oukil, S., Bali, F. \& Halliche, D. Adsorption and kinetic studies of methylene blue on modified HUSY zeolite and an amorphous mixture of $\gamma$-alumina and silica. Sep. Sci. Technol. 55, 2642-2658 (2020).

51. Uyar, G., Kaygusuz, H. \& Erim, F. B. Methylene blue removal by alginate-clay quasi-cryogel beads. React. Funct. Polym. 106, 1-7 (2016).

52. Gupta, V. K. Equilibrium uptake, sorption dynamics, process development, and column operations for the removal of copper and nickel from aqueous solution and wastewater using activated slag, a low-cost adsorbent. Ind. Eng. Chem. Res. 37, 192-202 (1998).

53. Zhirong, L., AzharUddin, M. \& Zhanxue, S. FT-IR and XRD analysis of natural Na-bentonite and Cu(II)-loaded Na-bentonite. Spectrochim. Acta Part A Mol. Biomol. Spectrosc. 79, 1013-1016 (2011).

54. Ferraro, J. R. The Sadtler Infrared Spectra Handbook of Minerals and Clays (Sadtler Research Laboratories, 1982).

55. Jawad, A. H. \& Abdulhameed, A. S. Mesoporous Iraqi red kaolin clay as an efficient adsorbent for methylene blue dye: Adsorption kinetic, isotherm and mechanism study. Surf. Interfaces 18, 100422 (2020).

56. Shattar, S. F. A., Zakaria, N. A. \& Foo, K. Y. Acid modified natural clay as a judicious solution for the successive treatment of ametryn. Desalin. Water Treat. 103, 1-10 (2018).

57. Caglar, B., Afsin, B., Tabak, A. \& Eren, E. Characterization of the cation-exchanged bentonites by XRPD, ATR, DTA/TG analyses and BET measurement. Chem. Eng. J. 149, 242-248 (2009).

\section{Acknowledgements}

The authors acknowledge the financial support provided by Ministry of Higher Education Malaysia under the Fundamental Research Grant Scheme (FRGS/1/2021/STG05/USM/02/8) entitled "Fundamental assessment on the preparation and modification techniques of cellulose nanocrystals for environmental remediation and yield improvement" and Universiti Sains Malaysia Fellowship Scheme.

\section{Author contributions}

All the authors have made substantial contributions to the conception and design of the experiment. S.F.A.S contributed in terms of acquisition of data, analysis of data, and preparation of the article, and K.Y.F. contributed in terms of conceptualization, methodology and writing-review and editing.

\section{Competing interests}

The authors declare no competing interests.

\section{Additional information}

Supplementary Information The online version contains supplementary material available at https:/doi.org/ 10.1038/s41598-022-06254-z.

Correspondence and requests for materials should be addressed to K.Y.F.

Reprints and permissions information is available at www.nature.com/reprints.

Publisher's note Springer Nature remains neutral with regard to jurisdictional claims in published maps and institutional affiliations.

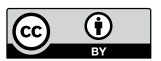

Open Access This article is licensed under a Creative Commons Attribution 4.0 International License, which permits use, sharing, adaptation, distribution and reproduction in any medium or format, as long as you give appropriate credit to the original author(s) and the source, provide a link to the Creative Commons licence, and indicate if changes were made. The images or other third party material in this article are included in the article's Creative Commons licence, unless indicated otherwise in a credit line to the material. If material is not included in the article's Creative Commons licence and your intended use is not permitted by statutory regulation or exceeds the permitted use, you will need to obtain permission directly from the copyright holder. To view a copy of this licence, visit http://creativecommons.org/licenses/by/4.0/.

(C) The Author(s) 2022 